\title{
A NOTE ON MEROMORPHIC $m$-VALENT STARLIKE FUNCTIONS
}

\section{ADRIANA CĂTAŞ}

Abstract. In the present investigation, we will derive sufficient conditions for starlikeness of meromorphic $m$-valent functions in the punctured disc.

Mathematics subject classification (2010): 30C45.

Keywords and phrases: Meromorphic $m$-valent functions, analytic functions, starlike functions, differential subordinations.

\section{REFERENCES}

[1] B.A. Frasin, G. Murugusundaramoorthy, New subclasses of meromorphic p-valent functions, J. of Ineq. in Pure and Appl. Math., 6, 3 (2005).

[2] S.S. Miller, P.T. Mocanu, On some classes of first order differential subordinations, Michigan Math. J., 32 (1985), 185-195.

[3] S.S. Miller, P.T. Mocanu, Gh. Oros, On a starlikeness condition for meromorphic functions, Mathematica (Cluj), 41(64), 2 (1999), 221-225. 